\title{
DISTRIBUTION OF MICRODISCHARGES AND INFLUENCE OF DIELECTRIC SURFACE ON OZONE YIELD
}

\author{
members T. MURATA \\ members Y. OKITA \\ members K. YASUOKA
}

\author{
non-members $M$. TATSUKAWA \\ (Toshiba Corporation) \\ (Tokyo Institute of Technology)
}

\begin{abstract}
The distribution of microdischarges in time and space, the influence of dielectric surface on microdischarges, and the characteristic of ozone generation were studied using electrical and optical methods. As a result, the phenomenon of a chain of microdischarges occurring in a brief period could be observed. In addition, it was found that the microdischarge characteristic, collective microdischarge phenomenon, and ozone yield varies according to the surface condition of the dielectric electrode. The ozone yield was high with a glass surface and low with a ceramic surface.
\end{abstract}

Key words: Dielectric barrier discharges, Ozone generation, Dielectric surface, Microdischarges

\section{INTRODUCTION}

When AC voltage is applied between metal and dielectric electrodes, many microdischarges occur in a pulsating manner. This phenomenon is generally called silent discharge. With respect to the generation of ozone by silent discharge, characteristics of individual microdischarges [1][2][3] and a macroscopic characteristic of silent discharge [4][5] have been studied by experimentation and computer modeling. But the phenomena occurring in an actual ozonizer, in which many microdischarges take places continuously, have not been fully understood. For example, the influence of a preceding microdischarge on succeeding ones and the field distortion due to charge accumulated on the dielectric surface have not been clarified. With the development of individual microdischarge, surface discharge occurs on the dielectric. We think these phenomena depend on the dielectric material. With respect to the relationship between surface discharge and ozone generation, there are some questions which have yet to be answered. In order to realize the high ozone yield, it is important to select a suitable material for the dielectric electrode. There are, however, few reports on this problem.

The distribution of microdischarges in time and space, the influence of dielectric surface on microdischarge, the polarity effect of microdischarge and the characteristic of ozone generation were studied using electrical and optical methods.

\section{EXPERIMENT}

As shown in Fig. 1, a parallel plate arrangement with an effective discharge area of $19 \mathrm{~cm} \times 19 \mathrm{~cm}$ and the discharge gap of 0.7 to $1.3 \mathrm{~mm}$ was used for the ozonizer discharge unit. A medium-frequency, high-voltage power supply producing 1 to $2 \mathrm{kHz}$ rectangular wave current was used. Dry air whose dew point was below $-60^{\circ} \mathrm{C}$ was used as the working gas.

First, to examine the distribution condition of microdischarges, observation of discharge pattern, simultaneous measurement of discharge current and discharge emission, and measurement of the transferred charge were carried out. In these experiments, we used Pyrex glass having a conductive coating for the dielectric electrode and stainless steel for a water cooled metal electrode. Two types of conductive coating--SUS and NESA-were used. In particular the NESA-coated glass electrode, which was transparent, was used to observe the microdischarge pattern on the glass surface. The microdischarge emission was photographed and analyzed by a high-speed CCD camera system (Princeton Instruments' CSMA system, resolution: $5 \mathrm{nsec}$ ). We tried to observe the side view of microdischarge emission, too. Because the side view of microdischarges is integrated from near field to far field, it is difficult to distinguish individual microdischarge. We prepared a $1 \mathrm{~cm}$ wide glass electrode and photographed and analyzed the side view of microdischarges by the same CCD camera system.

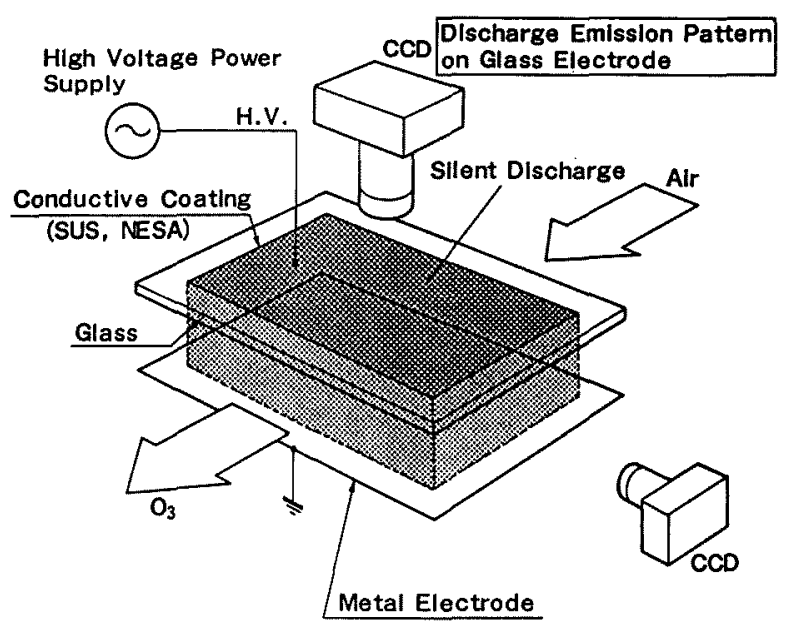

Fig. 1 Experimental set up

The transferred charge was calculated by integrating microdischarge current, measured by CT (Pearson 2100), using 
a digitizing signal analyzer (Tektronix DSA602). The discharge power was obtained as a product of the above discharge current and an applied voltage measured by a high-voltage probe (Tektronix P6015). To compensate for the 20 ns delay in CT rise time, the discharge light emission was also measured by a photomultiplier tube (Hamamatsu Photonix R106, rise time: less than $10 \mathrm{~ns}$ ) from the side of discharge gap.

Second, to examine the influence of the dielectric material on microdischarges and ozone generation, a glass electrode and an alumina ceramic $\left(\mathrm{Al}_{2} \mathrm{O}_{3}\right)$ electrode were compared. The electrical properties of both materials are listed in table 1. The measurements of ozone yield were performed using a double-side cooling electrode configuration. A watercooling metal jacket was fitted to the back of each dielectric electrode. Ozone concentration was measured by means of a UV spectrophotometer (Ebara EG-2001A). In order to distinguish between surface and bulk dielectric characteristics, an alumina electrode having a glazed surface was prepared and compared with a non-glazed alumina electrode. Its properties are listed in table 1.

Table 1 Electrical Properties of Dielectric Electrodes

\begin{tabular}{|c|c|c|c|c|c|}
\hline \multirow[b]{2}{*}{ Dielectric } & \multicolumn{2}{|l|}{ Bulk } & \multicolumn{3}{|c|}{ Surface } \\
\hline & $\begin{array}{c}\text { Dielectric } \\
\text { Constant } \\
\varepsilon \mathrm{r}\end{array}$ & $\begin{array}{r}\tan \delta \\
(\%)\end{array}$ & $\begin{array}{l}\text { Secondary } \\
\text { Electron } \\
\text { Emission }\end{array}$ & $\begin{array}{c}\text { Resistance } \\
(\Omega)\end{array}$ & $\begin{array}{c}\text { Roughness } \\
\mathbf{R m a x} \\
(\mu \mathrm{m})\end{array}$ \\
\hline Pyrex Glass & 5 & 1.03 & $0.5^{*}$ & $1.2 \times 10^{13}$ & 0.01 \\
\hline Alumina & 10 & 0.73 & 0.7 & $1.0 \times 10^{11}$ & 5.0 \\
\hline $\begin{array}{l}\text { Glazed } \\
\text { Alumina }\end{array}$ & 10 & 0.73 & $0.5^{*}$ & $1.4 \times 10^{13}$ & 0.03 \\
\hline
\end{tabular}

*Secondary electron escape probability[6] for $\mathrm{SiO}_{2}$

\section{RESULTS AND DISCUSSION}

\subsection{DISTRIBUTION OF MICRODISCHARGES IN TERMS OF TIME}

Fig. 2 shows the typical example of current waveform when the ozonizer having glass(G)-metal(M) electrode configuration was operated with a rectangular wave current source. It can be seen that a high-peak pulse current overlaps with the basic rectangular current. The pulse current in $\mathrm{G}(+) \mathrm{M}(-)$ polarity differs from that in $\mathrm{G}(-) \mathrm{M}(+)$ polarity.



Fig.2 Current waveform for glass (G)-metal(M) electrode configuration
Fig. 3 shows two types of current and discharge light emission waveforms measured through a lens from one side of discharge gap for $\mathrm{G}(+) \mathrm{M}(-)$ as the polarity of the applied voltage. One of them is small current pulse as shown in Fig.3 (a). The pulse width of discharge is approximately $10 \mathrm{~ns}$. In terms of the transferred charge, a small current pulse corresponds to individual microdischarge. Another is high peak pulse current as shown in Fig. 3(b). A current which was several times to tens of times greater than those in microdischarges was observed for as long as about $100 \mathrm{~ns}$.

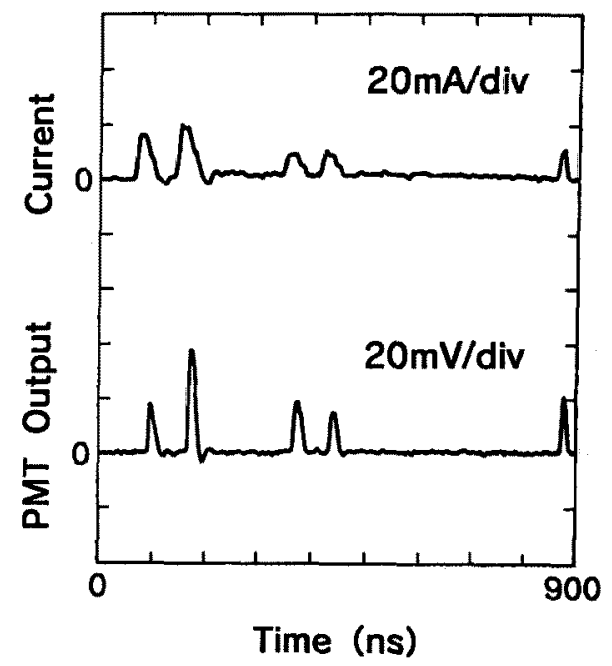

(a) Microdischarges

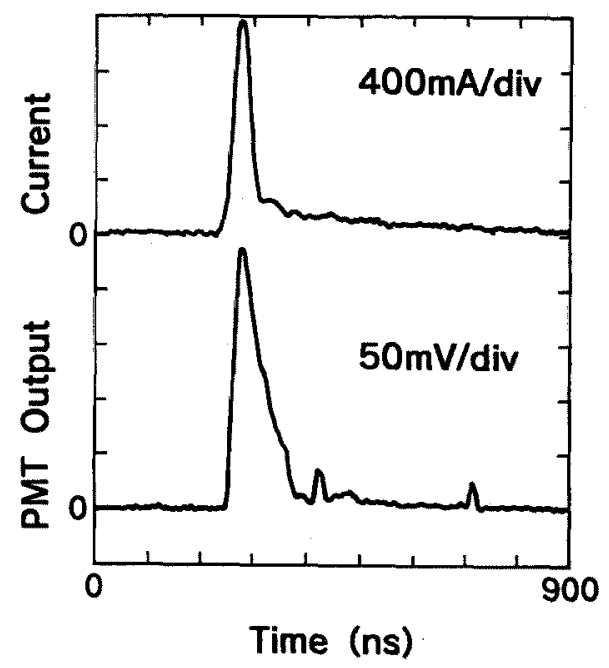

(b) A group of microdischarges

Fig. 3 Discharge current pulse and discharge emission (PMT output), $[\mathrm{G}(+) \mathrm{M}(-)]$

\subsection{DISTRIBUTION OF MICRODISCHARGES IN TERMS OF SPACE}

To investigate the high peak pulse of the current, the microdischarge emission pattern on the glass electrode was photographed through the NESA-coated glass by the high- 
speed CCD camera. We used the signal of the high peak pulse of the current for the trigger source of CCD camera.

The top view of microdischarges for the exposure time of $100 \mathrm{~ns}$ corresponding to the width of high peak pulse current is shown in Fig. 4. We can observe that a group of microdischarges occurs locally. We tried to observe the side view of the same phenomena. Fig. 5 (a) shows the result for the exposure time of $20 \mathrm{~ns}$. A group of microdischarges can be observed. When the exposure time is reduced to $6 \mathrm{~ns}$, we can observe the details of the microdischarge's development in a group as shown in Fig. 5 (b). This exposure time corresponds to the development time of streamer, approximately [7]. We can observe a discharge channel in the left side of this figure and only surface discharge in the middle of this figure. We think surface discharge is the final phase of microdischarge in this polarity. It is clarified that a chain of microdischarges occurs in a group.

From these results, the high peak pulse of current is considered due to not a single microdischarge but to a group of microdischarges. One reason for the occurrence of a group of

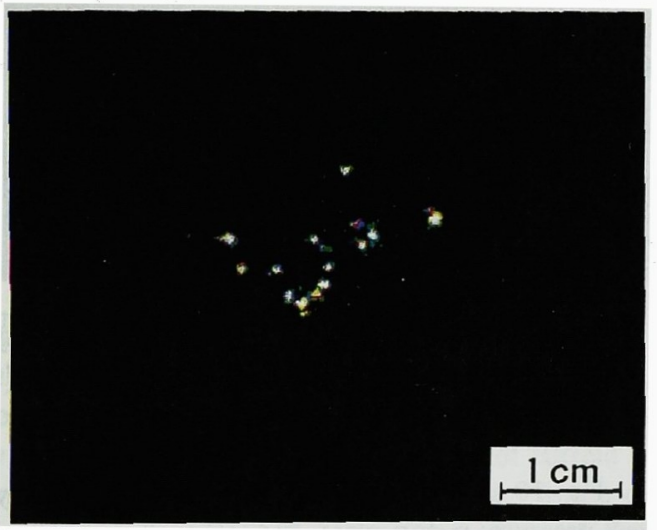

Fig. 4 Top view of a group of microdischarges (exposure time; 100ns), $[\mathrm{G}(+) \mathrm{M}(-)]$

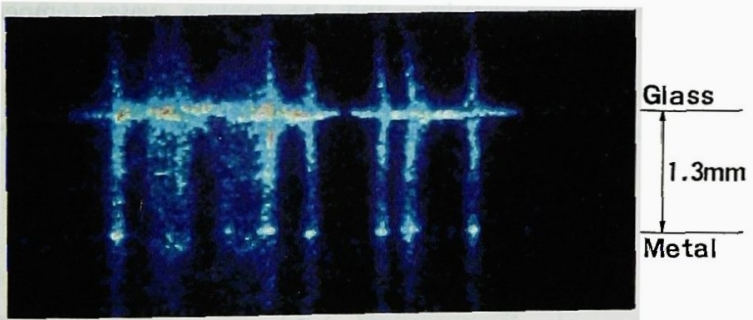

(a) Exposure time; $20 \mathrm{~ns}$



(b) Exposure time; $6 \mathrm{~ns}$

Fig. 5 Side view of a group of microdischarges $[\mathrm{G}(+) \mathrm{M}(-)]$ microdischarges is that UV emission from a preceding microdischarge pre-ionizes the air and release the secondary electrons from electrode, then triggers succeeding microdischarges. The surface discharges diffuse to the relative large area of dielectric surface. UV emission from surface discharges may affect the occurrence of succeeding microdischarges.

\subsection{TRANSFERRED CHARGE AND POLARITY EFFECT}

We evaluated the transferred charge of microdischarge by integrating individual small pulse current, using a digital signal analyzer. The transferred charge $\Delta \mathrm{Q}$ per each microdischarge (gap: $1.3 \mathrm{~mm}$ ) is about $350 \mathrm{pC}$ for $\mathrm{G}(-) \mathrm{M}(+)$ polarity and about $170 \mathrm{pC}$ for $\mathrm{G}(+) \mathrm{M}(-)$ polarity, the former being about two times greater than the latter. Where these values were obtained by averaging 50 microdischarges. Fig. $6(\mathrm{a})$ and (b) show the side views of microdischarges for $\mathrm{G}(-$ ) $\mathrm{M}(+)$ and $\mathrm{G}(+) \mathrm{M}(-)$, respectively. In the case of $\mathrm{G}(-) \mathrm{M}(+)$ polarity, the glass electrode becomes a cathode, hence positive ions having low mobility are accumulated on the glass surface. Because of this, a intense field occurs along the glass plane, causing surface discharge easily. As a result, a diffused discharge channel is observed. In the case of $\mathrm{G}(+) \mathrm{M}(-)$ polarity, the metal electrode becomes a cathode, hence the cathode spot is easy to fix. As a result, a discharge channel becomes thin. We can understand the size of discharge channel affects the value of the transferred charge.

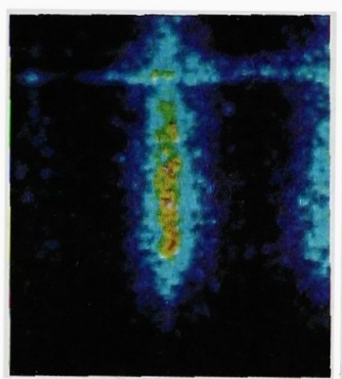

(a) $\mathrm{G}(-) \mathrm{M}(+)$

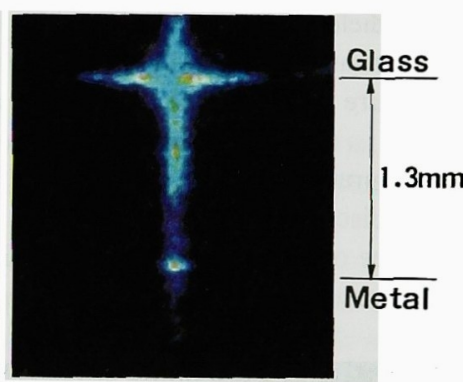

(b) $\mathrm{G}(+) \mathrm{M}(-)$
Fig. 6 Polarity effect of microdischarge

The Qmax of a group of microdischarges obtained by integrating high peak pulse current is $100 \mathrm{nC}$ for $\mathrm{G}(+) \mathrm{M}(-)$ polarity and $40 \mathrm{nC}$ for $\mathrm{G}(-) \mathrm{M}(+)$ polarity. Qmax $\Delta \mathrm{Q}$ assumed as the average number of microdischarges in a group was about 500 at largest for $\mathrm{G}(+) \mathrm{M}(-)$ and about 100 at largest for $\mathrm{G}(-$ ) $\mathrm{M}(+)$. This suggests that in the case of $\mathrm{G}(+) \mathrm{M}(-)$ polarity, a preceding microdischarge will cause succeeding microdischarges to occur more easily.

\subsection{INFLUENCE OF DIELECTRIC MATERIAL}

To study the influence of dielectric material on the characteristics of microdischarges described above, an experiment was carried out using an alumina ceramic $\left(\mathrm{Al}_{2} \mathrm{O}_{3}\right)$ electrode. Fig. 7 shows the current waveform obtained with the alumina ceramic(C)-metal(M) electrode configuration. 


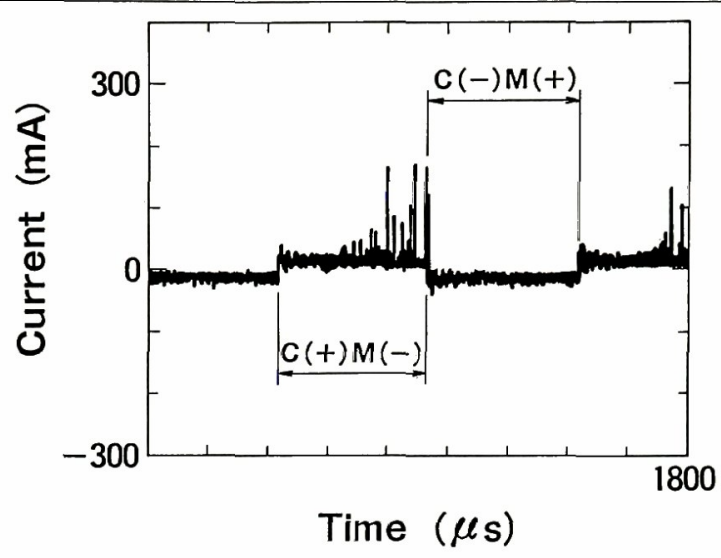

Fig. 7 Current for the alumina ceramic(C)-metal(M) electrode configuration

Compared with the results obtained with the glass(G)-metal(M) electrode configuration shown in Fig. 2, the high peak pulse current due to a group of microdischarges was not evident for $\mathrm{C}(-) \mathrm{M}(+)$ polarity. The maximum charge Qmax of a group of microdischarges for $\mathrm{C}(+) \mathrm{M}(-)$ polarity giving a high peak pulse current was $100 \mathrm{nC}$, which was the same as the Qmax of the glass-metal electrode configuration. With respect to the charge $\Delta \mathrm{Q}$ of microdischarge, the alumina ceramic electrode was nearly the same as the glass electrode for both polarities.

We compared between the side view of microdischarges for glass electrode and it for alumina ceramic electrode. Fig. 8 shows the side views for dielectric(-)-metal(+) polarity. The same sizes of microdischarges are observed with both dielectric electrodes. With glass(G)-metal(M) electrode configuration, we can observe a group of microdischarges in the exposure time of $100 \mathrm{~ns}$ like the opposite polarity shown in Fig.5. With alumina ceramic(C)-metal(M) electrode configuration, we could not observe any groups of microdischarges for this polarity. It was confirmed that the absence of collective phenomena wipes out the high peak pulse of current for dielectric(-)-metal(+) polarity as shown in Fig.7.

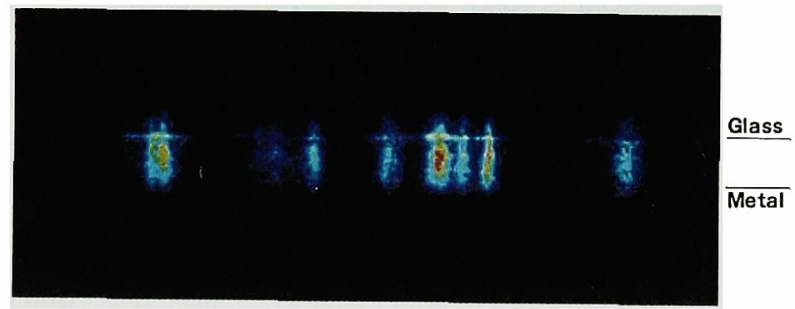

(a) $\operatorname{Glass}(\mathrm{G})$-metal(M) electrode configuration

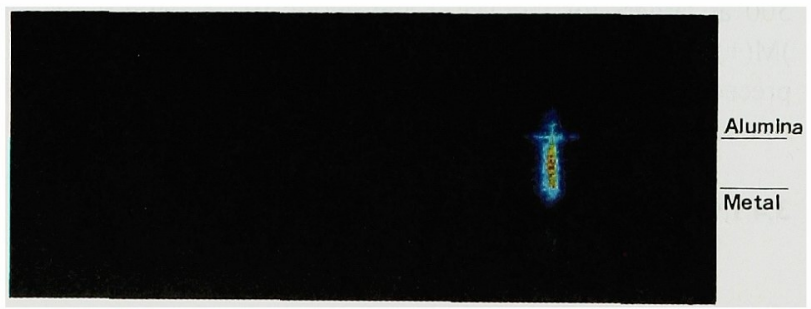

(b) Alumina ceramic(C)-metal(M) electrode configuration

Fig. 8 Side view of microdischarges for dielectric(-)-metal $(+)$ polarity (exposure time; 100ns)
Furthermore, It should be noted that with the alumina ceramic electrode many bright filaments were observed at the side view of discharge gap in the case of long exposure time of $5 \mu \mathrm{s}$ as shown in Fig. 9. We think the origin of bright filament is that microdischarges occur on the same projection points of the rough alumina surface many times. Alumina is a sintered material, therefore it has larger surface roughness than glass as shown in Table 1.

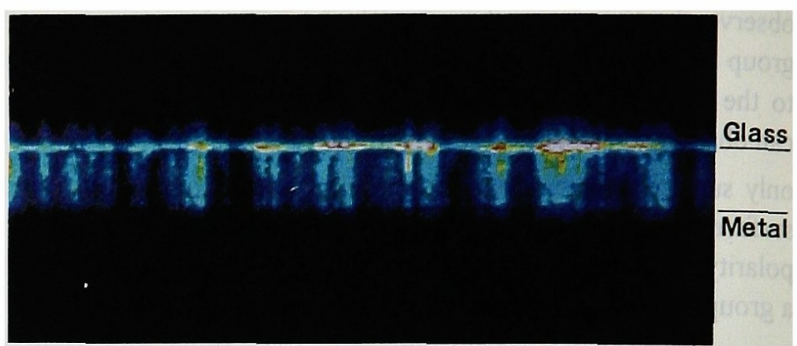

(a)Glass(G)-metal(M) electrode configuration

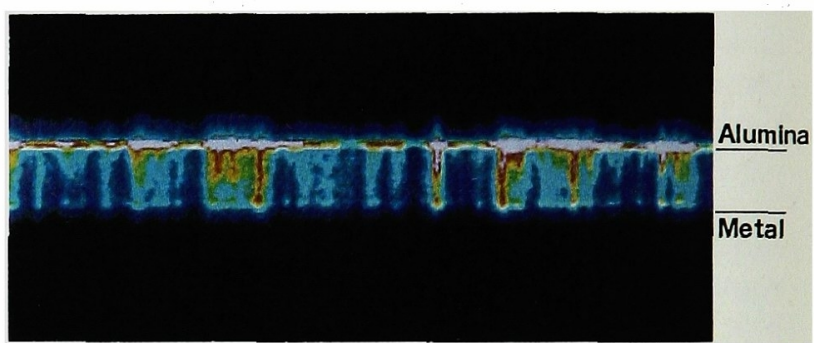

(b)Alumina ceramic(C)-metal(M) electrode configuration

Fig. 9 Side views of microdischarges for dielectric $(+)$ metal(-) polarity (exposure time; $5 \mu \mathrm{s}$ )

Fig. 10 shows the relationship between ozone yield $\eta$ and gas pressure $\mathrm{p}$ for glass and alumina ceramic used as dielectric materials. A water-cooling metal jacket was fitted to the back of each dielectric electrode to configure a double side cooling ozonizer. Here the discharge gap was $0.7 \mathrm{~mm}$, the power density $1.2 \mathrm{~kW} / \mathrm{m}^{2}$, and the cooling water temperature $15^{\circ} \mathrm{C}$.

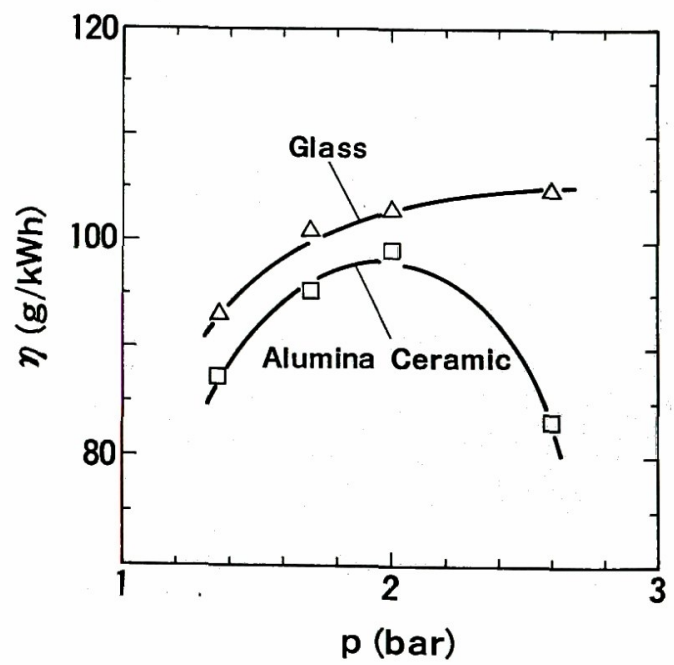

Fig. 10 Dependence of ozone yield on gas pressure with glass and alumina ceramic 
The ozone yield $\eta$ obtained with an alumina electrode is less than $\eta$ obtained with a glass electrode at the same gas pressure. With the glass electrode, the ozone yield $\eta$ increases with gas pressure up to above $2.6 \mathrm{bar}$. With the alumina electrode, the ozone yield $\eta$ increases with gas pressure up to 2 bar too; however $\eta$ decreases steeply above this pressure. We observed the bright microdischarges occurred in the form of filaments in such conditions. We considered a reason of the low ozone yield with alumina electrode was the local heating on the same projection points of the rough surface where microdischarges occurred many times.

\subsection{INFLUENCE OF DIELECTRIC SURFACE}

We studied the influence of the dielectric electrode surface alone, with the difference in dielectric constant between glass and alumina (5 vs. 10) ignored. An experiment was carried out using an alumina ceramic electrode glazed on the surface. The current waveforms obtained with the glazed alumina ceramic(GC)-metal(M) electrode configuration are shown in Fig. 11. The high peak pulse current that was not observed with $\mathrm{C}(-) \mathrm{M}(+)$ in Fig. 6 reappeared with $\mathrm{GC}(-) \mathrm{M}(+)$. Thus, it can be seen that the characteristics of microdischarges with the glass $(G)$-metal $(M)$ electrode configuration, shown in Fig. 2, were again obtained. It was confirmed, therefore, that the absence of a group of microdischarges in dielectric(-)metal $(+)$ polarity has nothing to do with the dielectric bulk, and that only the dielectric electrode surface is involved.

In the field of high voltage engineering, partial discharges (PD) were measured and analyzed generally. We know there are some kind of PD according to the surface conditions of dielectric materials. Ito et al. [8] explained that the low surface resistivity made small pulses of current known as swarming pulsive microdischarges (SPMD). In the case of SPMD, only small pulses of current are observed for both polarity of applied voltage. Gosho and Saeki [9] have investigated the influence of UV irradiation on the initial electrons from dielectric surface. They found that the high peak pulse of current disappears for only dielectric(-)-metal $(+)$ polarity by increasing the intensity of UV irradiation.

We think the secondary electron emission plays the important role for the collective phenomena of microdischarges

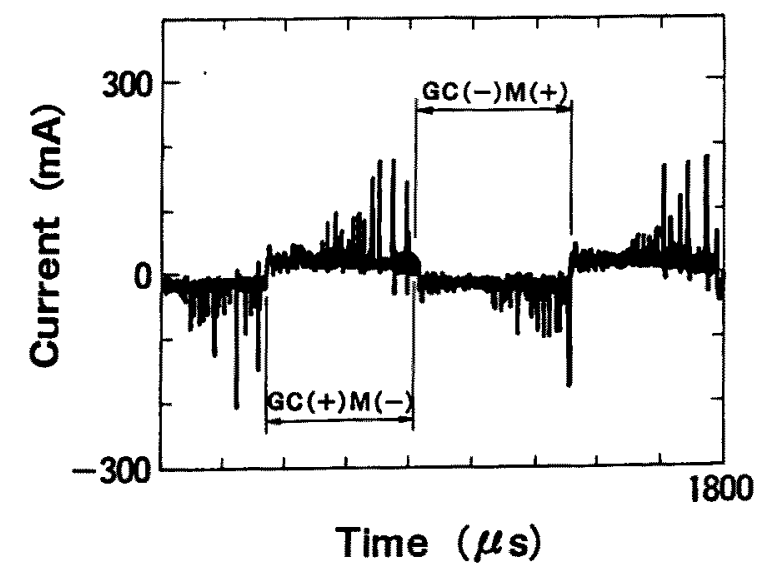

Fig. 11 Current in the case of glazed alumina ceramic(GC)metal(M) electrode configuration like the former results of UV irradiation. Alumina has high secondary electron emission probability as shown in Table 1. Therefore we think electrons were released from alumina surface equally by UV irradiation of the preceding microdischarges. Furthermore alumina has low surface resistivity, probably the transferred charge on dielectric surface becomes uniform distribution easily, the collective phenomena hardly occurs.

Fig. 12 shows the relationship between ozone yield $\eta$ and ozone concentration $\mathrm{C}$ for each of glass, alumina ceramic, and glazed alumina ceramic used as dielectric electrodes. At a ozone concentration of $20 \mathrm{~g} / \mathrm{Nm}^{3}$, the glass and glazed alumina ceramic gave nearly the same ozone yield $\eta(89 \mathrm{~g} / \mathrm{kWh})$, while the alumina ceramic yielded only $79 \mathrm{~g} / \mathrm{kWh}$. We can see the low ozone yield with alumina electrode is improved by means of glazing the surface.

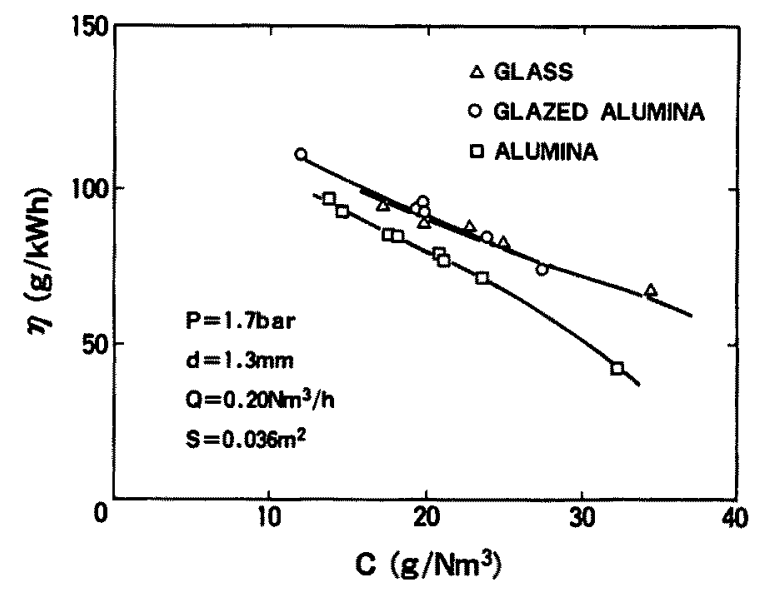

Fig. 12 The dependence of ozone yield $\eta$ on ozone concentration $\mathrm{C}$ with glass, alumina and glazed alumina

The surface properties of glass, alumina, and glazed alumina are different as shown in Table 1. The dielectric surface offering high ozone yield have high surface resistance and low surface roughness. It was clarified that the surface condition of the dielectric material used for an electrode was especially important in terms of ozone yield.

\section{CONCLUSIONS}

The distribution of microdischarges in time and space and the influences of dielectric surface on microdischarges and on ozone generation were studied. As a result, it was found that the distribution of microdischarges in time was not uniform and that a chain of microdischarges occurred locally for a brief period of approximately $100 \mathrm{~ns}$. It was also found that the surface condition of the dielectric material used for an electrode was especially important in terms of ozone yield (glass offers high ozone yield, while ceramic offers low ozone yield). Furthermore, it was found that the surface condition of dielectric material influences the collective phenomena of microdischarges.

(Manuscript Received January 18, 1996, revised June 14, 1996) 


\section{REFERENCES}

[1]K. Yoshida and H. Tagashira, IEE Jpn., ED-91-82 (1991)

[2]D. Braun et al., Plasma Sources Sci. Technol., 1 , 166(1992)

[3]B. Eliasson et al., J. Phys. D: Appl. Phys., 20, 1421(1987)

[4]D. Braun and G. Pietsch, Proc. 11th Ozone

World Congr. (San Francisco), vol. 1, (1993) S-4-20

[5]N. Tabata et al., Trans. Static Electr. Jpn., 7, 3.150(1983)

[6]R. Alig and S. Bloom, J. Appl. Phys., 49, $\underline{6}, 3476(1978)$

[7]D. Braun et al., J. Phys. D: Appl. Phys., 24, 564(1991)

[8]T. Ito et al., Trans. IEE Jpn. A, 95, 1, 335(1975)

[9]Y. Gosho and M. Saeki, Proc. 5th Int. Symp. High Voltage Eng., 23.24, Braunschweig (1987)



Takaaki Murata was born in Mie, Japan, in 1961. He received B.S. and M.S. degrees in Electrical Engineering from Mie University in 1983 and 1985 respectively. In 1985, he joined Heavy Apparatus Engineering Laboratory of Toshiba Corporation, and has been engaged in development of RF and AC discharges' technology for $\mathrm{CO} 2$ lasers and ozonizers. Mr. Murata is a member of IEE of Japan and the Japan Society of Plasma Science and Nuchear Fusion Research.

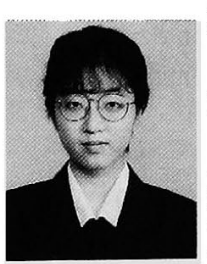

Miki Tatsukawa was born in Fukui, Japan, in 1964. She received B.S. and M.S. degrees in physics from Science University of Tokyo in 1988 and 1990 respectively. In 1990, she joined Heavy Apparatus Engineering Laboratory of Toshiba Corporation, and she was engaged in development of $\mathrm{CO} 2$ lasers and ozonizers. Since 1995, she has been in Multimedia Division of Toshiba.



Yuji Okita was born in Tokyo, Japan, in 1966. He received B.S. degree in applied physics from Okayama University of Science in 1990. He has been with Toshiba Factory Automation Systems Engineering Corporation, and engaged in the development of pulse lasers and ozonizers at Toshiba Corporation. Mr. Okita is a member of

IEE of Japan.

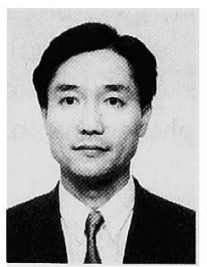

Kouichi Yasuoka was born in Shizuoka, Japan, in 1955. He received B.S., M.S. and D.S. degrees from Tokyo Institute of Technology in 1978.1980,1983 respectively. In 1983, he joined Heavy Apparatus Engineering Laboratory of Toshiba Corporation, where he was engaged in development of high power pulsed lasers. In April 1995, he transferred to the Tokyo Institute of Technology, where he was appointed associate professor of General Electrical Engineering. Dr. Yasuoka is a member of IEE of Japan, the Japan Society of Applied Physics, the Japan Society of Plasma Science and Nuclear Fusion Research, Laser Society of Japan and IEEE. 